\title{
Nature's Batik: A Computer Evolution Model of Diatom Valve Morphogenesis
}

\author{
Katie Bentley, ${ }^{1, *}$ Eileen J. Cox, ${ }^{2}$ and Peter. J Bentley ${ }^{1}$ \\ ${ }^{1}$ Department of Computer Science, University College London, London, UK \\ ${ }^{2}$ Department of Botany, The Natural History Museum, London, UK
}

\begin{abstract}
This paper describes a novel computer simulation that uses evolution to design functioning raphid pennate diatom valves. The model of valve morphogenesis used is based on current theories that highlight the importance of cytoskeletal elements in valve development. An "organic" negative imprint is grown in a grid-based system, using both local and global rules to dictate grid cell states. Silica then diffuses out into all remaining grid cells. This model is shown to generate raphid pennate diatom valves capable of functioning as cell walls. At every stage of development the generated valves are consistent with observations of real diatom valve growth. This model of diatom valve morphogenesis is interestingly similar to the negative technique used by artists in batik painting.
\end{abstract}

Keywords: Morphogenesis, Raphid Diatom, Computer Simulation, Genetic Algorithm.

\section{INTRODUCTION}

Natural evolution uses processes of development to grow highly adapted organisms. Understanding morphogenesis, the generation of form, will therefore aid the development of well-designed, well-adapted, efficient devices, such as robots, processors, and circuits. Organisms that incorporate inorganic material into their morphology offer a rare and exciting opportunity to learn, from nature, efficient mechanisms for the manipulation of materials for our technology.

Diatoms are single celled photosynthetic protists that thrive in many environments such as seas, lakes, and damp soils. With over 200000 species, they are the second most diverse group of photosynthetic organisms and produce approximately $20 \%$ of the world's carbon fixation. ${ }^{1,2}$ Most interestingly they possess an external shell or frustule of amorphous silica that functions as a cell wall. This frustule is made up of two halves, each comprising a valve and a number of girdle bands. Diatom valves are often beautifully patterned, with regularly arranged pores perforating the valves. ${ }^{3}$ As a cell wall, the frustule is structurally very strong and resistant to enzyme attack and also functions as a defense against grazing and infection.

*Author to whom correspondence should be addressed.
However, some diatoms are susceptible to parasitism by chytrids, oomycetes, and protozoa and infraspecific variation in susceptibility has been observed. ${ }^{4-7}$ Although it is unclear whether there is a consistent point of entry for the parasites. Diatom cell walls confer rigidity and precise shape to the enclosed protoplasts. However, they must also allow the transport of small molecules to and from the protoplast and allow for its expansion during the mitotic cell cycle. ${ }^{8}$

Despite a variety of studies over the last few decades, ${ }^{9}$ the fine control of nanometer to micrometer scale pattern during diatom valve morphogenesis remains poorly understood. Transmission electron microscopical (TEM) studies reveal that the cytoskeleton (the network of cytoplasmic structural components, including actin filaments and microtubules ${ }^{9}$ ) is intimately involved in valve patterning and may also incorporate the use of cytoplasmic organelles or other inclusions as moulds for different valvar components. ${ }^{10-12} \mathrm{Schmid}^{13}$ suggested that the process of using material to block the deposition of silica is comparable to the negative technique used in batik, where the outline of an image is drawn with wax and the dye only soaks into the cloth where there is no wax. Thus color is incorporated where wax is absent.

Our model is only concerned with the morphogenesis of raphid pennate diatoms, which are of particular 
biological interest to one of us (E.J.C.) and have not previously been the subject of computer models. It is based on the premise that silica is deposited around organically produced templates, the protoplast effectively generating a negative imprint of the valve pattern. ${ }^{13}$ This paper explores the evolution of a negative space mechanism for the manipulation of silica, to produce a functional, patterned shape, similar in form to a raphid pennate diatom valve. Parkinson and co-workers presented a theoretical model, based on diffusion-limited aggregation (DLA), which produced centriclike patterns, ${ }^{14}$ although cell biologists would argue that observed patterns are not explicable by the physics of diffusion alone, ${ }^{8,13,16-18}$ but that cytoplasmic components and processes are modulating valve morphogenesis.

\subsection{Valve Morphogenesis in Raphid Diatoms}

Two major symmetry groups of diatoms can be recognized, centric and pennate. Centric diatoms usually exhibit radially symmetrical valves, with an annular pattern center, whereas pennate diatoms have approximately bilateral symmetry and an elongate pattern center. ${ }^{3}$ Within the pennate group, raphid diatoms are characterized by the possession of a double-slit (raphe) system, which is the elongate pattern center and has an intrinsically asymmetrical mode of development. ${ }^{18}$

Diatoms reproduce predominantly by mitosis, each daughter cell producing one new valve (the hypovalve) after cytokinesis but retaining one of the parent valves as the older valve (epivalve) of each daughter. Because the new valves are formed within (and are constrained by) the parent frustule, there is often (but not invariably) a gradual decrease in average cell size over a series of mitotic divisions. ${ }^{19,20}$ Within a certain critical size range, diatoms can be induced to reproduce sexually and thereby to restore the maximum size for that species. ${ }^{7}$

During formation of the valves, silica is transported to the silica deposition vesicle (SDV) where it diffuses in and adheres to already consolidated silica in an accretive manner. ${ }^{13}$ Valve formation occurs in a series of stages (Figs. 1-6) that always occur in the same order, although taxon specific patterns are also observed. ${ }^{21}$ (The variation in valve morphology between species and the consistency of morphology within species together indicate that morphology is genetically controlled.) Silicification begins with the raphe sternum, first forming a longitudinal

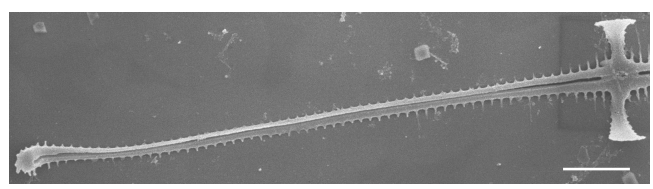

Fig. 1. Craspedostauros australis. Raphe slit showing very early virga development. Valve center to right hand side of picture. Scale bars represent $2 \mu \mathrm{m}$.

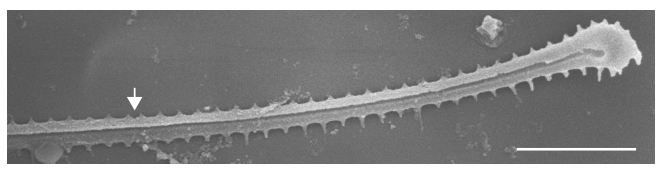

Fig. 2. Craspedostauros australis. Detail of other end of raphe system. Point where secondary side of raphe is completed indicated by arrowhead. Scale bars represent $2 \mu \mathrm{m}$.

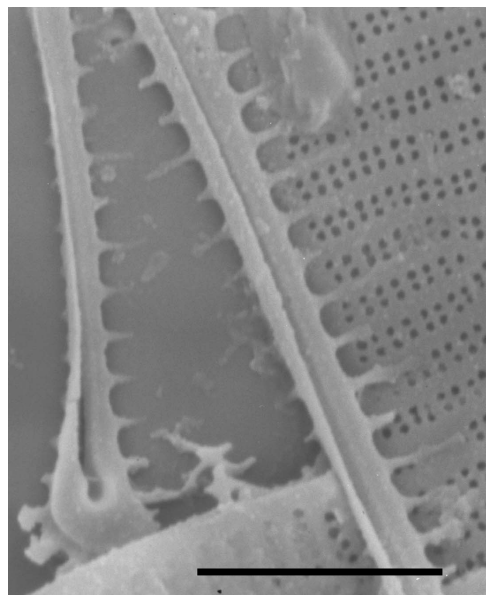

Fig. 3. Craspedostauros australis. Early raphe overlying part of mature valve, showing identical spacing of forming virgae and mature striae. Scale bars represent $2 \mu \mathrm{m}$.

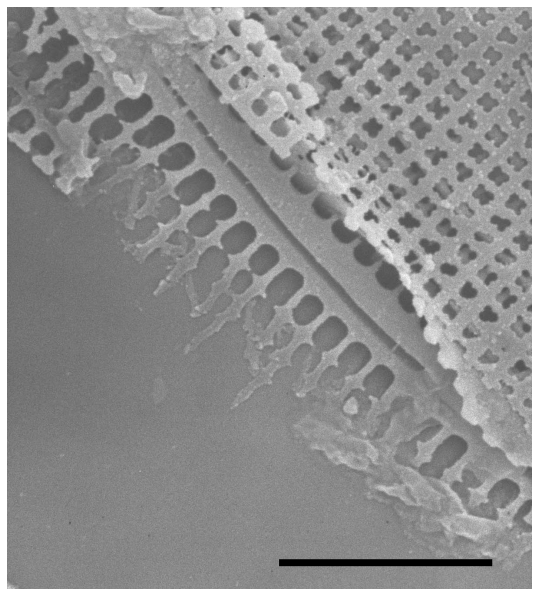

Fig. 4. Craspedostauros australis. Vimines beginning to form near raphe slit. Scale bars represent $2 \mu \mathrm{m}$.

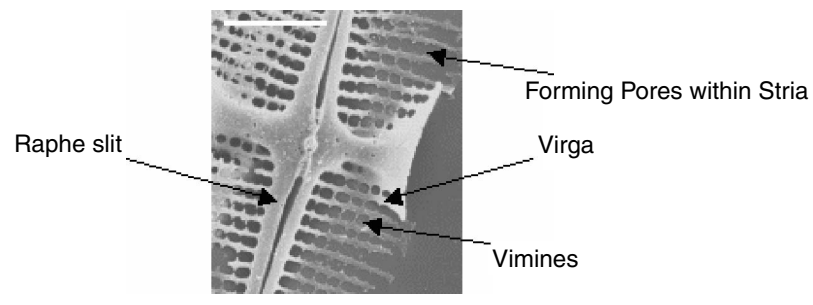

Fig. 5. Craspedostauros australis. Slightly later stage with longer virgae and more vimines. Scale bars represent $2 \mu \mathrm{m}$. 


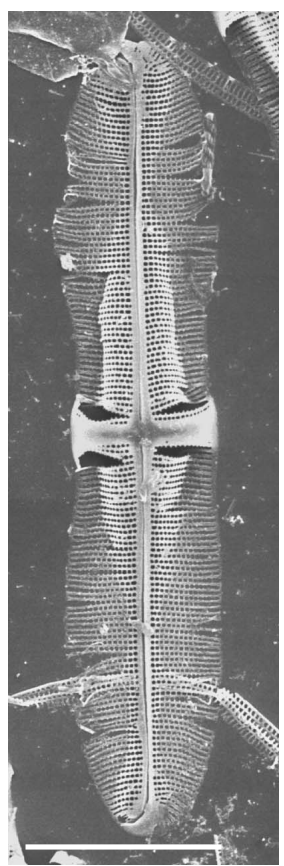

Fig. 6. Craspedostauros australis. External view of almost complete valve. Scale bars represent $10 \mu \mathrm{m}$.

rib that curls around as it approaches the cell apices and meets the extending shorter ribs on the secondary side. ${ }^{3,9,18}$ The initial position of the SDV and of the raphe system seems to be controlled by the position of the microtubule center (MC), ${ }^{13,18}$ whose orientation also sets that of the valve pattern. ${ }^{13}$ After enclosure of the raphe slits, ribs of silica (virgae) that will ultimately lie between the striae grow out in a transapical direction, with the cross connections (vimines) developing later to define the pores (Fig. 5) 18,22,23 (often between 0.1 and $0.5 \mu \mathrm{m}$ in diameter). As silica polymerizes onto the enclosed forming valve the SDV expands apically and transapically. ${ }^{24}$ The sequential formation of virgae, vimines, and fine pore occlusions suggests that areas where silicification is initially prevented by the presence of organic material, e.g., between forming virgae, must subsequently be opened up to allow silicification of the vimines. ${ }^{8}$ Tubulin and actin have been implicated in pattern formation, as microtubules and microfilaments are variously associated with the SDV during morphogenesis, ${ }^{10,24,25}$ and their inhibition affects the raphe position and pore spacing respectively. ${ }^{13,26,27}$

\subsection{Cellular Automata}

A cellular automaton (CA) is a grid-based, discrete computational system in which every grid cell can be in one of a set of states. A cell's state is changed in accordance with a finite set of rules, relating to the states of the cell's local neighbors, within a given radius (Fig. 7). The state of every cell in the grid is iteratively updated every time step. For a more thorough introduction to CA's, see

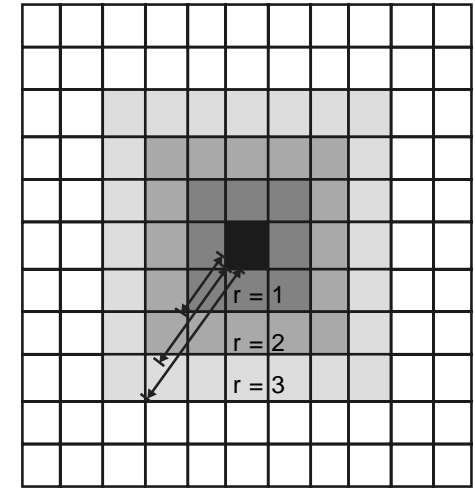

Fig. 7. A grid cell (shown in black) and its local neighbors of radius 1,2 , and 3 .

Wuensche. ${ }^{28}$ CA's have been used to model pattern formation in many domains, such as mammalian coat patterns, ${ }^{29}$ microstructures, ${ }^{30}$ seashell patterns, ${ }^{31}$ embryological pattern formation, ${ }^{32}$ and aesthetic pattern formation, ${ }^{33}$ mainly because of CA's general property of local interactions producing global, emergent phenomena.

\subsection{Genetic Algorithm}

The genetic algorithm is an evolutionary algorithm used for problem solving (e.g., design ${ }^{34,35}$ ) or for modeling natural evolution. Populations of individuals, each individual comprising a genotype and a corresponding phenotype, are maintained by the computer. The fitness of each individual is measured by using a fitness function to assess the quality of the phenotype with respect to some objective or environment. "Better-adapted" individuals are selected as parents that then give rise to the next generation of offspring, inheriting their parents' genes through random crossover and mutation operators. Over a number of generations, the evolutionary algorithm creates individuals with higher fitnesses. For a good introduction to GA's, see Holland. ${ }^{36}$

\section{MATERIALS AND METHODS}

The model was programmed in $\mathrm{C}++$ and all experiments were performed on a standard $1.8-\mathrm{GHz}$ PC workstation with graphics programmed in openGL. In the model, the valve is grown in several distinct stages, employing both local and global rules. The parameters involved in these stages, which ultimately govern the shape and patterning of the valve, are evolved to improve the valve's functionality as a cell wall. The model is highly abstracted, the CA having only seven possible states during growth. These states are classed as either "organic" or "siliceous" and so, once the valve has grown, it can be further reduced to a two-state system. The possible states and the class to which they belong are detailed in Table I. All parameters of the model discussed in this section are shown in italics 
Table I. Possible states for grid cells and their classes.

\begin{tabular}{llc}
\hline Cell state & $\begin{array}{c}\text { Material } \\
\text { represented }\end{array}$ & Class $(0=$ organic, $1=$ siliceous $)$ \\
\hline 0 & Nothing & - \\
1 & Raphe & 0 \\
2 & Silica & 1 \\
3 & Epitheca & 1 \\
4 & Striae & 0 \\
5 & Pore center & 0 \\
6 & Pore & 0 \\
\hline
\end{tabular}

in parentheses and relate either to initial model settings or to genes (Tables II and III).

\subsection{Valve Growth}

The valve is grown on a grid of size $2 x \mathrm{MAX} \times 2 y \mathrm{MAX}$, where $x \mathrm{MAX}$ and $y \mathrm{MAX}$ are set at the beginning of each experiment. The CA grid has all cells initialized in state 0 , meaning "nothing present." This is shown in Figure 8a, where $x \mathrm{MAX}$ and $y \mathrm{MAX}$ equal 5.

\subsubsection{Defining Epitheca Shape}

Hypovalve growth in diatoms is almost invariably restricted by the shape of the epitheca, as shown by SEM observations of developing virgae. Virgae are forced to curve and thus form the valve mantle when they impinge upon the epitheca. ${ }^{21}$ Epitheca shape must therefore first be defined, although for the purposes of the model an arbitrary shape can be chosen. In order to model the epitheca simply and effectively, epitheca shape is described by a number of points (controlpoints), between which lines are drawn, analogous to placing a rubber band around a set of pins. A more complex shape can be generated by the use of more points. Because many raphid pennate diatoms are both isopolar and bilaterally symmetrical, only the controlpoints in the bottom left quadrant of the grid need to be specified in the genotype. These are then reflected in the $x$ - and $y$-axes by a translation algorithm enforcing symmetry, to produce the full epitheca outline. The parameter $x$ MIN determines where the $x$-coordinate of a control point can lie; for example, in Figure $8 \mathrm{~b}$ this is 5. The first and last third of the control points lie between, but not including, 0 and $x \mathrm{MIN} / 2$. Thus $x \mathrm{MIN}$ constrains

Table II. Static parameters and their usual setting in experiments.

\begin{tabular}{lc}
\hline Static parameters & Setting \\
\hline$x \mathrm{MAX}$ & 40 \\
$y \mathrm{MAX}$ & 160 \\
controlpoints & 10 \\
MC $(x, y)$ & $(0,0)$ \\
PRADIUS & 2.1 \\
MRADIUS & 1.2 \\
MTIME & 5 \\
MRATEf & 0.4 \\
MRATEi & 20 \\
\hline
\end{tabular}

Table III. Genes, their order in the genotype, and the possible ranges for each.

\begin{tabular}{rll}
\hline & \multicolumn{1}{c}{ Gene } & $\begin{array}{c}\text { Possible range for } \\
\text { gene } G\end{array}$ \\
\hline 0 & packinDist & $0<G<x \mathrm{MAX}-1$ \\
1 & $x$ MIN & $0<G<x \mathrm{MAX}-1$ \\
2 & RapheWidth & $0<G<x \mathrm{MAX}-1$ \\
3 & StriaeRapheGap & $0<G<x \mathrm{MAX}-1$ \\
4 & Striae & $0<G<y \mathrm{MAX} / 4$ \\
5 & striaeWidth & $0<G<2 y \mathrm{MAX}$ \\
6 & RapheGap & $0<G<y \mathrm{MAX}$ \\
7 & radiusIdeal & $0.00 \leq G<10.00$ \\
8 & controlpoint $0(x)$ & $0.00 \leq G<1.00$ \\
9 & controlpoint $0(y)$ & $0.00 \leq G<1.00$ \\
10 & controlpoint $1(x)$ & $0.00 \leq G<1.00$ \\
11 & controlpoint $1(y)$ & $0.00 \leq G<1.00$ \\
12 & controlpoint $2(x)$ & $0.00 \leq G<1.00$ \\
13 & controlpoint $2(y)$ & $0.00 \leq G<1.00$ \\
14 & controlpoint $3(x)$ & $0.00 \leq G<1.00$ \\
15 & controlpoint $3(y)$ & $0.00 \leq G<1.00$ \\
16 & controlpoint $4(x)$ & $0.00 \leq G<1.00$ \\
17 & Controlpoint $4(y)$ & $0.00 \leq G<1.00$ \\
\hline
\end{tabular}

the width of the epitheca and also prevents the epitheca having tapered-out ends. The $y$-axis is divided into equal segments according to the number of control points. The control points each lie in one of these segments. This is essentially a way of generating endlessly different elliptical shapes. In practice, the specific locations of the $x$ - and $y$-coordinates are given by a decimal value between 0 and 1 , specifying, when scaled to the size of the segment, how far from the bottom and away from the $y$-axis the point lies within the segment. For example (Fig. 8b), the first control point is specified by $(0.6666,0.6666)$ in the genotype which, given that the segment is sized $3 \times 3$, translates as $(2,2)$ within that segment. Due to the position of the segment, this translates finally as $(-2,-9)$.

\subsubsection{Setting the Position of the Raphe}

It has been suggested that the presence of a raphe fiber prevents silicification where the raphe slit is forming. ${ }^{13}$ The model therefore postulates that raphe slit material (三 raphe fiber) grows along the $y$-axis in both directions, starting a certain distance (RapheGap) from a given start point $(M C)$ and within a given width (RapheWidth). Cells within this area with no radius 1 neighbors of state 3 (i.e., not close to the epitheca) have their state changed to 1 meaning "raphe slit material" (Fig. 8c).

\subsubsection{Simulation of SDV Growth and Silica Deposition}

All silica deposition occurs within the SDV, and the SDV expands as silica diffuses in and is accreted. ${ }^{8,9,13}$ For our model, the SDV is modeled simply as a rectangle with initial corner vertices defined by Eq. (1), where the vertices are labeled $a$ to $d$ clockwise from the top left hand 


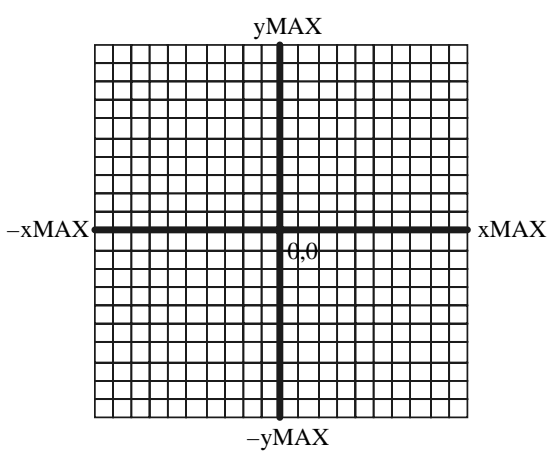

(a)

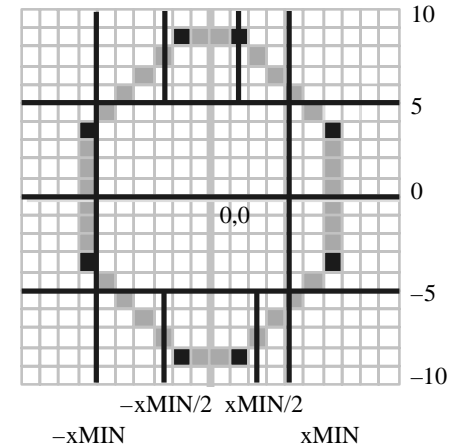

(b)

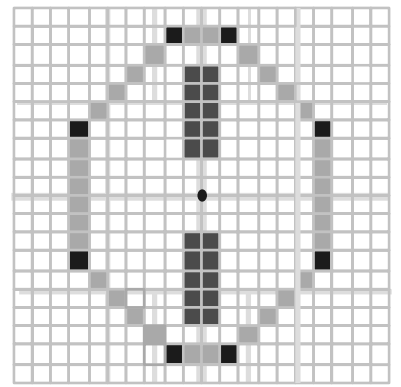

(c)

Fig. 8. (a) Initial grid, all cell states set to 0 , shown in white. (b) Control points shown in black, there are four on the left, which are mirrored on the right. Control points and the cells joining them shown in grey, are denoted by state 3 meaning "epitheca". (c) Raphe slit material is denoted by state 1 and shown in dark grey.

corner. Only cells of state 0 within the SDV box can be changed to state 2 (silica), i.e., class 0 and 1 material (organic and siliceous) in a CA cell within the SDV prevent silica deposition. State 0 cells within the SDV can only become state 2 if there is a state 2 cell in its radius 1 neighborhood. The SDV is initiated with all state 0 cells changed to state 2, i.e. full of silica. The SDV increases in size if $70 \%$ of the empty cells in the SDV have been filled with silica. The SDV expands along the $y$-axis until it reaches the epitheca, then along the $x$-axis, until it abuts the epitheca laterally.

$$
\begin{aligned}
& a=(M C x-2 \times \text { RapheWidth, MCy }+ \text { RapheGap }) \\
& b=(M C x, M C y+\text { RapheGap }) \\
& c=(M C x, M C y-\text { RapheGap }) \\
& d=(M C x-2 \times \text { RapheWidth, MCy }- \text { RapheGap })
\end{aligned}
$$

\subsubsection{Delimitation of Striae}

The scenario presented by $\mathrm{Schmid}^{8}$ invokes the use of spacer vesicles and organic matter to set the position and form of pores that form striae. A certain number (Striae) of blocks of material that mark out the striae are placed at a certain distance (StriaeRapheGap) from the raphe slit and are grown outward from the StriaeRapheGap (三 sternum) along specific trajectories. This was based on the observation that many pennates have parallel to radiate striae. These trajectories are calculated as follows: start points $(x 1, y 1)$ of the stria trajectory lines are equally spaced along the $y$-axis at a given distance from the raphe slit (StriaeRapheGap) on both sides. The end points: $(x 2, y 2)$ are calculated in polar coordinates $(r, \theta)$, where $r$ equals 300 for all experiments. $\theta$ is calculated for each stria by dividing the given $2 \pi$ radians into Striae equal segments. Then $x 2=r \cos \theta$, $y 2=r \sin \theta$.

Stria material is grown at a given thickness (StriaeWidth) along each line between the respective $(x 1, y 1)$ and $(x 2, y 2)$ until neighbors of radius 2 contain a cell of state 3 (it approaches the epitheca)(Fig. 9a). For the model, this process has to be initiated almost simultaneously with the SDV to ensure the formation of striae.

\subsubsection{Delimitation of Pores within Striae}

Pores are defined within striae by the outgrowth of vimines, once the virgae have reached a particular length, depending on the species. ${ }^{21}$ For each diatom taxon, mature pore diameter falls within a particular range and pores show consistent spacing along a stria. For the purposes of the model, pore centers are set using a simplified packing algorithm, to generate pore position as in Figure 10. The pore centers are placed at a given distance (PackingDist) from each other along the first vertical line nearest the $y$-axis of cells in all striae, then at equal PackingDist and PackingDist/2 intervals from those along the stria trajectory gradient. Similarly, to attain a consistent size for each taxon, pores are assumed to have an ideal radius (radiusIdeal) as the end point of their developmental trajectory. Pores are initialized with size radius $M A X=$ radiusIdeal +10 , for all experiments, and pore radius decreases as the amount of silica in the cell's

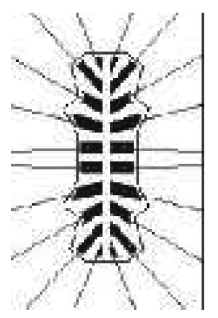

(a)

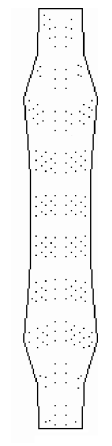

(b)
Fig. 9. (a) Radiating striae. (b) Pore centers placed within striae. 


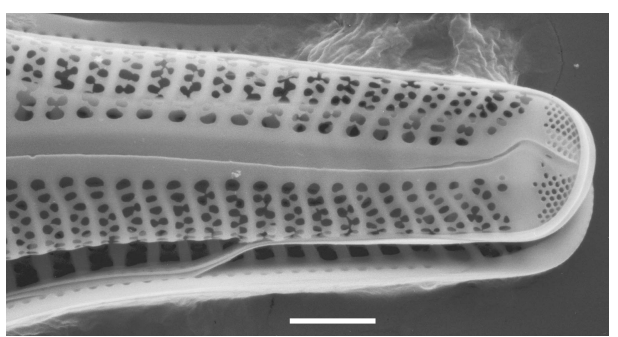

Fig. 10. Gomphonema truncatum Vimines fusion creating offset pores within the striae. Scale bar represents $2 \mu \mathrm{m}$.

local neighborhood increases. The number of cells $N$ of state 2 in the neighborhood of a pore center with radius $r=2 \times$ radiusMAX is calculated every third time step (to save on computation time). This specifies by how much the pore material reduces at each assessment in accordance with Eq. (2).

$$
r=\left\{\begin{array}{l}
\text { radiusIdeal }+\frac{50 \times(\text { packingDist } \times 0.1)}{(1+N)} \\
\quad \text { if } N>\text { RadiusMAX } / 4 \\
\text { radiusMAX otherwise }
\end{array}\right.
$$

Once all pore radii are calculated, any cell within the stria that is situated within a pore radius is set to state 6 (pore material). Pore centers, however, remain as state 5. To aid calculation at the next evaluation, remaining state 4 cells (三 stria material) are reset to 0 . This means that half pores can occur, where the center is within the stria boundary but the radius traverses it. The conversion from decimal distance calculations to integer cell state changes incurs a nonperfect pore arrangement, tantamount to noise (Fig. 9b).

\subsection{Computer Evolution of Valve Morphologies}

A standard generational GA is used to evolve parameters of the model diatom. Genotypes are initialized randomly, with evolution running for 100 generations using population sizes of 100. Each genotype consists of the 18 genes shown in Table III, relating directly to the parameters for growth shown. Each member of the population is grown and then assessed by the fitness function described in Section 2.2.1. The top $10 \%$ of the population become the parents of the next generation. The highest scoring member genotype is transferred unchanged into the next generation (elitism). The other 99 members of the next generation are produced using crossover at a random point in the genotype of two randomly chosen parents (with replacement). All 99 are then subject to creep mutation with a probability of 0.08888 . On average 1.6 genes are mutated per member of the population, which is usual for a standard GA. MRATE $i$ is the creep value subtracted from integer genes. MRATE $f$ is the creep value subtracted from decimal encoded genes (Table II).

\subsubsection{Fitness Function}

Diatom cell walls, while protecting the enclosed protoplast against infection, must also allow molecular exchange with the external environment. Circular molecules and pathogens with radii MRADIUS and PRADIUS, respectively, are placed with their centers in each CA cell on the valve. Molecules are allowed to move randomly a set number of times (MTIME), whereas the pathogens remain static. This is to reflect the probability of molecules moving along concentration gradients and diffusing through pores, while pathogen attacks usually occur at much lower frequencies. If no class 1 material (silica) or state 0 (nothing) in all the CA cells in its radius is encountered, passage through the valve is permitted. (The rule about state 0 precludes the formation of impossible valves.) Points, $m$ for a molecule or $p$ for a pathogen, are then awarded.

The fitness is a function of the two processes shown in Eq 3. Fitness is thus higher for a valve that does not allow pathogen entry but still allows the maximum amount of molecular movement. This is a highly simplified model of cell wall function but is used so that the resulting pattern emerges from the interaction of two necessary functions of the valve. It precludes enforcing or unwittingly "pre-programming" the pattern by selecting for a certain arrangement and size of raphe, striae, and pores.

The penalty conditions that set fitness to -20000000 are set in order to ensure that impossible valves do not grow or propagate through subsequent generations. To save on computation time, if these penalty conditions are met, valve growth is not allowed to start, analagous to an organism possessing an expressed lethal gene Eq. (3).

$$
\text { fitness }=\left\{\begin{array}{c}
-20000000 \\
\text { if packingDist }<\text { radiusIdeal } \times 2 \\
-20000000 \\
\text { if radiusIdeal }>\text { striaeWidth } / 2 \\
-20000000 \\
\text { if Striae } \times \text { striaeWidth } \\
>\text { ValveLength } \\
\text { moved }- \text { attacked otherwise } \\
\text { moved }=\sum m \\
\text { attacked }=\sum\left(p \pi P R A D I U S^{2}\right)
\end{array}\right.
$$

\section{RESULTS AND DISCUSSION}

In 15 evolutionary runs of the model to maximize the fitness function, the static parameters were set as in Table II (type A runs). The mean fitness was 2093, with standard deviation of 892.13. In a further 10 runs (type B runs), MRATE $i$ was set to a random integer between 1 and 100 and MRATEf was set to a random decimal 


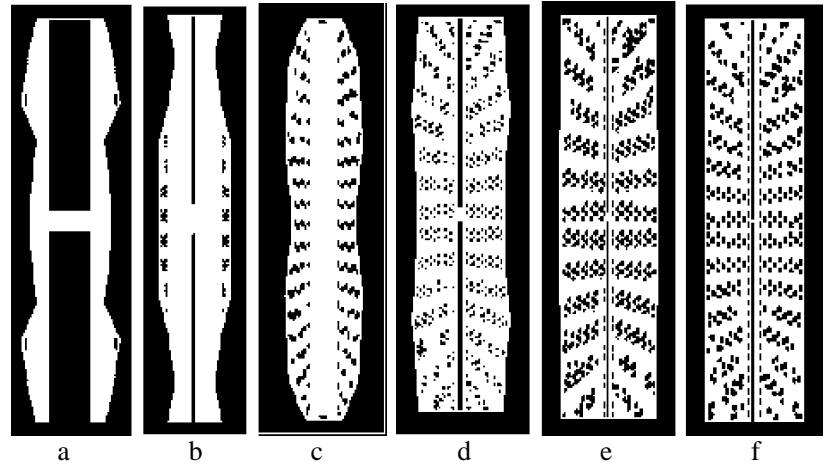

Fig. 11. Evolved valves. Valve $a$ is an example of a highly unfit valve, it was the highest scoring valve in the first generation of a type B run. The wide raphe leaves it open to attack by pathogens. Valves $b, c$, and $d$ are final generation valves from type A runs. The lower scoring ones are thinner ( $x$ MIN being smaller) and have not grown an effective raphe slit. Valve $d$ has a better score as it has a larger surface area due to a greater $x$ MIN value; it has also grown pores that allow molecular movement but not attack by pathogens (radiusIdeal is between 1.2 and 2.1). Valves $e$ and $f$ are both final generation valves of type B runs. They have far higher scores as the surface area has been maximized while pore size and raphe slit width have been minimized. The number and width of striae is also maximized, while gaps between striae and raphe have been minimized.

between 0 and 1 . Mean fitness rose to 5184, with a standard deviation of 1740. Improving the mutation operators allowed populations to reach a higher fitness. A typical evolutionary run took $8-12 \mathrm{~h}$.

\subsection{Evolved Valves}

A cross-section of evolved valves is shown in Figure 11, and their respective genes and fitnesses are given in Table IV. Both high and poor scoring (low fitness) valves are shown to illustrate the full effects of the evolutionary algorithm.

\subsection{Growth Patterns}

Setting the initial SDV box slightly to the left of the $M C$ meant that the growth of the primary silica rib (Fig. 12) was consistent with EM observations. This emerged from the interaction of silica diffusion local rules, the SDV initial box placement, and the prior placement of raphe material. Gradual decrease in the size of the pore material within the striae allowed the characteristic sequence of virga growth followed by vimen growth to occur. Figure 12 shows the growth of the virgae and vimines, while Figure 13 shows the decrease in size of pore material as silica accumulates around it. An enlarged section (Fig. 14) shows the pore size decrease in more detail. The model has produced growth patterns comparable to those observed in raphid diatoms by EM (Figs. 1-6).

\subsection{Areas for Improvement of the Model}

This model is in its early stages and would therefore benefit from further exploration and development. There was no realistic selection pressure on valve outline so the fittest shape for the epitheca was a rectangle, which is very rarely seen in nature. However, an extra component could be added to the fitness function to reward for shear drop shapes, which would cope better with flow. ${ }^{37}$ More streamlined shapes may also favor moving over surfaces or through sediments, the typical habitats of most raphid diatoms. Stria trajectories and pore arrangements were similarly oversimplified. They failed to account for the occurrence of parallel, or intercalated, shorter striae and for the uniseriate rows of pores within striae, seen in many raphid diatoms. This could be overcome by the use of a variety of packing algorithms, for example, that new striae could emerge where there is space, rather than being globally positioned. Our CA model would also allow the

Table IV. Sample of evolved valve's fitnesses and genotypes.

\begin{tabular}{|c|c|c|c|c|c|c|}
\hline Valve & $\mathrm{a}$ & $\mathrm{b}$ & $\mathrm{c}$ & d & $\mathrm{e}$ & $\mathrm{f}$ \\
\hline Fitness & $-40 \_718$ & 1843 & 2136 & 4038 & 6258 & 6685 \\
\hline packinDist & 38 & 4 & 6 & 6 & 7 & 8 \\
\hline$x \mathrm{MIN}$ & 23 & 16 & 13 & 32 & 37 & 37 \\
\hline RapheWidth & 31 & 3 & 15 & 3 & 2 & 3 \\
\hline StriaeRapheGap & 18 & 20 & 8 & 3 & 2 & 2 \\
\hline Striae & 18 & 16 & 20 & 16 & 14 & 18 \\
\hline StriaeWidth & 19 & 15 & 10 & 17 & 22 & 17 \\
\hline RapheGap & 8 & 12 & 154 & 6 & 4 & 2 \\
\hline radiusIdeal & 9.265_175 & 1.198_767 & $1.786 \_889$ & $1.214 \_118$ & $1.587 \_725$ & 1.779_229 \\
\hline controlpoint $0(x)$ & $0.179 \_052$ & $0.267 \_885$ & $0.066 \_463$ & $0.239 \_570$ & 0.278_939 & $0.539 \_293$ \\
\hline controlpoint $0(y)$ & 0.447_951 & $0.012 \_336$ & $0.512 \_589$ & $0.385 \_418$ & 0.194_739 & $0.568 \_163$ \\
\hline controlpoint $1(x)$ & $0.853 \_450$ & $0.190 \_313$ & $0.641 \_316$ & $0.885 \_647$ & $0.442 \_885$ & $0.593 \_188$ \\
\hline controlpoint $1(y)$ & $0.189 \_459$ & $0.486 \_837$ & $0.682 \_882$ & $0.454 \_176$ & 0.661_061 & $0.598 \_743$ \\
\hline controlpoint $2(x)$ & 0.457_076 & $0.547 \_197$ & 0.499_161 & $0.394 \_147$ & $0.814 \_783$ & $0.533 \_769$ \\
\hline controlpoint $2(y)$ & 0.527_757 & 0.107_358 & $0.345 \_067$ & $0.168 \_523$ & $0.150 \_304$ & $0.117 \_862$ \\
\hline controlpoint $3(x)$ & $0.093 \_081$ & $0.048 \_347$ & $0.009 \_485$ & $0.023 \_353$ & $0.058 \_443$ & $0.265 \_664$ \\
\hline controlpoint $3(y)$ & $0.371 \_258$ & $0.189 \_740$ & $0.080 \_178$ & 0.001_025 & $0.542 \_070$ & 0.591_907 \\
\hline controlpoint $4(x)$ & 0.195_929 & $0.085 \_885$ & $0.214 \_515$ & $0.628 \_376$ & $0.262 \_612$ & $0.093 \_600$ \\
\hline controlpoint $4(y)$ & $0.499 \_649$ & $0.498 \_434$ & $0.502 \_548$ & $0.157 \_860$ & $0.524 \_644$ & 0.018_738 \\
\hline
\end{tabular}



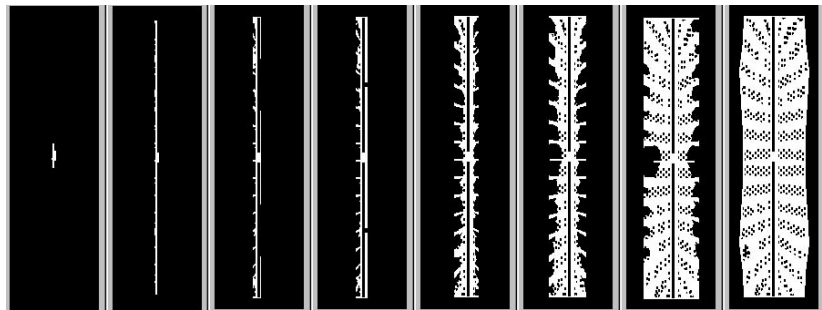

Fig. 12. Frames showing the growth of valve $d$.

substructure and pore occlusions seen in many diatom pores to be simulated but would require a larger CA grid. $x \mathrm{MAX}$ and $y \mathrm{MAX}$ were relatively small, the number of control points was fixed at 10 , the packing algorithm was the same throughout runs, and the $M C$ was set to $(0,0)$ to minimize the program run time. However, larger grid sizes allow for more intricate patterning as one cell is translated as one pixel and alternate packing algorithms can be implemented to great effect (Fig. 15).

It did prove possible to simulate valves in which the raphe does not lie centrally along the long axis, mimicking the situation observed in cymbelloid diatoms, although the model has not modified valve outline. Offsetting the MC offsets the patterning without the need to recalculate or change the model. Figure $15 \mathrm{~b}$ shows a valve grown with an offset $M C$ where all parameters were set by hand. It would be interesting to investigate these properties in further experiments using evolution.

Although there is currently much interest in the biochemistry of silicification and the nanofabrication of consolidated silica in diatom valves, ${ }^{38-40}$ variation in the form of silica deposited occurs on a finer scale than the valve features with which we have been concerned. Similarly, we have assumed that the position of the SDVs (within the confines of the parent cell) reduces the direct influence of the external medium on silica deposition.

There are several other aspects in which this first model simplifies wall morphogenesis. It was assumed that morphology was primarily controlled by genetics, rather than attempting to incorporate the effects of environmental

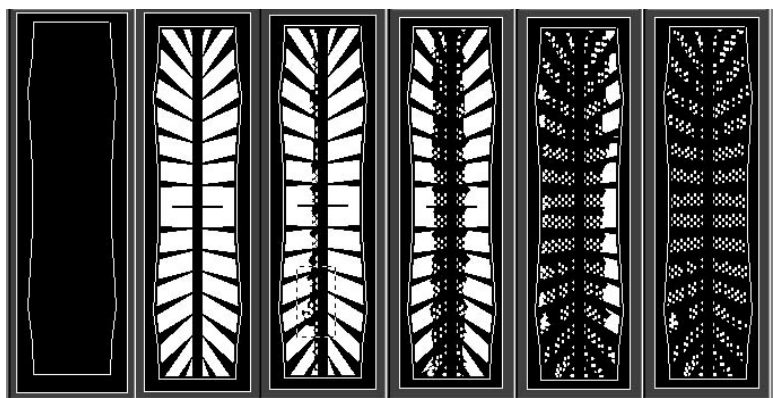

Fig. 13. Frames showing in white the epitheca outline and the shrinking of organic material to form pores during growth of valve $d$. Silica is diffusing as in Figure 12. The dotted box in the third frame is the section whose growth is shown enlarged in Figure 14.

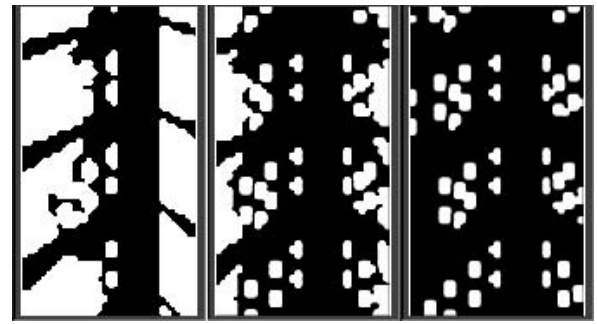

Fig. 14. Three stages in the growth of the section enlarged from Figure 13 showing the organic material in the striae (shown in white) reduce down to the radiusIdeal to form the pores, as the amount of silica around it increases; the silica is not shown.

variables on morphology. However, it could also be argued that until we have a clearer understanding of the interaction between the environment and diatom valve morphology it is difficult to set up suitably realistic hypotheses to model. There are relatively few experimental studies of the effects of varying environmental regimes on morphology. ${ }^{41-48}$ Similarly, the fitness function tested does not represent the only factors that affect morphology. Other factors such as locomotion and buoyancy ${ }^{9}$ could be incorporated, but the fitness function could easily be extended to include these. Further simulations could also be carried out where the various static parameters are changed. Arguably, the use of developmental genetic encoding would be more biologically plausible than the current genetic encoding and should be explored. It has also been shown that symmetry arises spontaneously in such systems. ${ }^{49,50}$

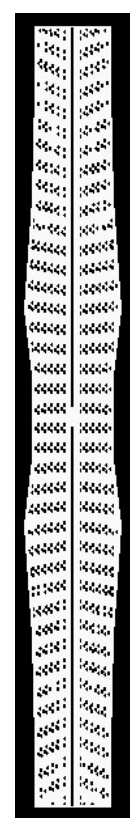

(a)

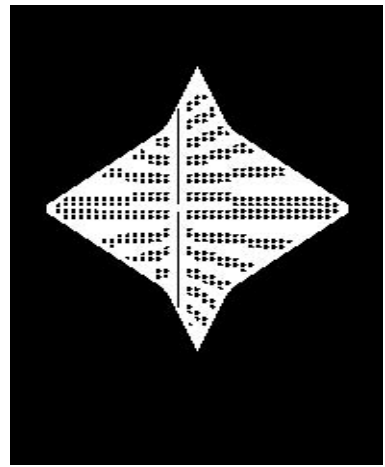

(b)
Fig. 15. Valves grown without evolution. (a) $x \mathrm{MAX}=70, y \mathrm{MAX}=$ 320. (b) $M C(-10,0)$. Both use an alternate packing algorithm where pore centers are set in horizontal rows. 


\section{CONCLUSIONS}

This model has generated raphid pennate diatom valves exhibiting some of the functions of cell walls. At each stage of development the generated valves were consistent with observations on real diatom valve growth.

Simulated models are extremely useful for investigating, visualizing, and developing theories of morphogenesis. It is the intention of this paper to inspire further model-based experiments and to try to bridge the gap between the disparate fields of computer science and biology for the exploration of morphogenesis.

The results of this work suggest that nature could manipulate silica in a way similar to how aesthetic patterns are created with Batik.

Acknowledgments: This work was funded by Science Applications International Corporation (SAIC). SEM was carried out at The Natural History Museum, London, and the support of Alex Ball and Chris Jones is acknowledged.

\section{References and Notes}

1. H. du Buf, M. Bayer, S. Droop, R. Head, S. Juggins, S. Fisher, H. Bunke, M. Wilkinson, J. Roerdink, G. P. Cristobal, H. Shahbazkia, and A. Ciobanu, Diatom identification: A double challenge called ADIAC. Proceedings of the 10th International Conference on Image Analysis and Processing, Venice, Italy (1999), pp. 734-739.

2. D. G. Mann and S. J. M. Droop, Biodiversity, biogeography and conservation of diatoms. In Biogeography of Freshwater Algae, edited by Jørgen Kristiansen, Developments in Hydrobiology, Kluwer Academic Publishers (1996), Vol. 118, pp. 19-32.

3. F. E. Round, R. M. Crawford, and D. G. Mann. The Diatoms: Biology and Morphology of the Genera, Cambridge Univ Press, MA (1990).

4. H. M. Canter, Fungal and protozoan parasites and their importance in the ecology of the phytoplankton. Annu. Rep., Freshwater Biol. Assoc. 47, 43 (1979).

5. H. M. Canter and G. H. M. Jaworski, Some observations on the alga Fragilaria crotonensis kitton and its parasitism by two chytridaceous fungi. Ann. Bot. 49, 429 (1982).

6. H. M. Canter and G. H. M. Jaworski, A further study on parasitism of the diatom Fragilaria crotonensis Kitton by chytridaceous fungi in culture. Ann. Bot. 52, 549 (1983).

7. D. G. Mann, The species concept in diatoms. Phycologia 38, 437 (1999).

8. A.-M. M. Schmid, Wall morphogenesis in Coscinodiscus wailesii Gran et Angst. II. Cytoplasmic events of valve morphogenesis. In Proceedings of the 8th Diatom Symposium, Paris 1984, edited by M. Ricard (1986), pp. 293-314.

9. J. Pickett-Heaps, A.-M. M. Schmid, and L. A. Edgar, The cell biology of diatom valve formation. Prog. Phycol. Res. 7, 1 ( 1990).

10. L. A. Edgar and J. D. Pickett-Heaps, Valve morphogenesis in the penante diatom Navicula cuspidata. J. Phycol. 20, 47 (1984).

11. L. A. Edgar, Fine structure of Caloneis amphisbaena (Bacillariophyceae). J. Phycol. 16, 62 (1980).

12. E. J. Cox and G. M. Kennaway, Studies of valve morphogenesis in pennate diatoms: Investigating aspects of cell biology in a systematic context. In Proceedings of the 17th Int. Diatom Symp., Ottawa 2002, edited by M. Poulin (in press).

13. A.-M. M. Schmid, Valve morphogenesis in diatoms: A patternrelated filamentous system in pennates and the effect of APM, colchcine and osmotic pressure. Nova Hedwigia 33, 811 (1980).
14. J. Parkinson, Y. Brechet, and R. Gordon, Centric diatom morphogenesis: A model based on a DLA algorithm investigating the potential role of microtubules. Biochim. Biophys. Acta 1452, 89 (1999).

15. J. D. Pickett-Heaps, Morphogenesis of the labiate process in the araphid diatom Diatoma vulgare. J. Phycol. 25, 79 (1989).

16. J. D. Pickett-Heaps, D. H. Tippit, and J. A. Andreozzi, Cell division in the pennate diatom Pinnularia. IV. Valve morphogenesis. Biol. Cell. 35, 295 (1979).

17. J. D.Pickett-Heaps, S. Cohn, A.-M. M. Schmid, and D. H. Tippit, Valve morphogenesis in Suirella. J. Phycol. 24, 35 (1988).

18. E. J. Cox, Diatoms: The evolution of morphogenetic complexity in single celled plants. In Developmental Genetics and Plant Evolution, edited by Q. C. B. Cronk, R. M. Bateman, and J. A.Hawkins, Taylor and Francis (Philadelphia), Bristol, PA (2002) pp. 459-492.

19. J. D. MacDonald, On the structure of the diatomaceous frustule, and its genetic cycle. Ann. Mag. Nat. Hist., Ser. 4 3, 1 (1869).

20. E. Pfitzer, Über den bau und die zellteilung der diatomeen. Bot. Zeitung, 27, 774 (1869).

21. E. J. Cox, Variation in patterns of valve morphogenesis between representatives of six biraphid diatom genera (Bacillariophyceae). J. Phycol. 35, 1297 (1999).

22. E. J. Cox and R. Ross, The striae of pennate diatoms. Proceedings of the 6th Symposium on Recent and Fossil Diatoms, edited by R. Ross, (1980), pp. 267-278.

23. C. Brett and K. Waldron, Physiology and Biochemistry of Plant Cell Walls, Chapman and Hall, London (1996).

24. C. W. Li and B. E. Volcani, Morphogenesis of the labiate process in centric diatoms. Protoplasma 124, 10-29, 30-41, 147-156 (1985).

25. M. L. Chiappino and B. E. Volcani, Studies on the biochemistry and fine structure of silica shell formation in diatoms. VII. Sequential cell wall development in the pennate Navicula pelliculosa. Protoplasma 93, 191 (1977).

26. G. S. Blank and C. W. Sullivan, Diatom mineralization of silicic acid. VII. Influence of microtubule drugs on symmetry and pattern formation in valves of Navicula saprophila during morphogenesis. J. Phycol. 19, 294 (1983).

27. S. A. Cohn, J. Nash, and J. D. Pickett-Heaps, The effect of drugs on diatom valve morphogenesis. Protoplasma 149, 130 (1989).

28. A. Wuensche and M. J. Lesser, The Global Dynamics of Cellular Automata; An Atlas of Basin of Attraction Fields of OneDimensional Cellular Automata, Santa Fe Institute Studies in the Sciences of Complexity, Addison-Wesley, Reading, MA (1992).

29. E. Bonabeau, From classical models of morphogenesis to agentbased models of pattern formation. In Proceedings of the 3rd Conference on Artificial Life, edited by C. Langton (1997), pp. 191-211.

30. B. Basanta, P. J. Bentley, M. A. Miodownik, and E. A. Holm, Evolving cellular automata to grow microstructures. Proceedings of the 6th European Conference on Genetic Programming (EuroGP 2003), 14-16 April, 2003.

31. M. Markus and I. Kushc, CA for modelling the shell pigmentation of moluscs. J. Biol. Syst. 3, 999 (1995).

32. S. Kumar and P. J. Bentley, The ABCs of evolutionary design: Investigating the evolvability of embryogenies for morphogenesis. In Genetic and Evolutionary Computation Conference (GECCO '99), July 14-17, 1999, Orlando, FL, USA (1999), pp. 164-170.

33. K. Bentley, Exploring aesthetic pattern formation. In Proceedings of the 5th Annual International Conference on Generative Art (GA2002), Milan (2002), Section 20.1.

34. Creative Evolutionary Systems, contributing editors P. J. Bentley and D. W Corne, Morgan Kaufmann Publishers (2001).

35. Evolutionary Design by Computers, contributing editor P. J. Bentley, Morgan Kaufmann (1999).

36. J. A. Holland, Adaptation in Natural and Artificial Systems, MIT Press, Cambridge, MA (1975).

37. R. Gordon, N. K. Björklund, G. G. C. Robinson, and H. J. Kling, Sheared drops and pennate diatoms. Nova Hedwigia 112, 289 (1996). 
38. N. Kröger, R. Deutzmann, C. Bergsdorf, and M. Sumper, Speciesspecific polyamines from diatoms control silica morphology. Proc. Nat. Acad. Sci. U.S.A. 97, 14133 (2000).

39. N. Kröger and M. Sumper, Diatom cell wall proteins and the cell biology of silica biomineralization. Protist 149, 213 (1998).

40. W. H. van de Poll, E. G. Vrieling, and W. W. C. Gieskes, Location and expression of frustulins in the pennate diatoms Cylindrotheca fusiformis, Navicula pelliculosa, and Navicula salinarum (Bacillariophyceae). J. Phycol. 35, 1044 (1999).

41. M. E. Schultz, Salinity-related polymorphism in the brackish-water diatom Cyclotella cryptica. Can. J. Bot. 49, 1285 (1971)

42. E. J. Cox, Morphological variation in widely distributed diatom taxa: Taxonomic and ecological implications. In Proceedings of the 13th International Diatom Symposium, Italy 1994, edited by D. Marino and M. Montressor, Koeltz, Koenigstein (1995), pp. 335-345.

43. R. Trobajo, E. J. Cox, and X. D. Quintana, The effects of some environmental variables on the morphology of Nitzschia frustulum (Bacillariophyta), in relation its use as a bioindicator. Nova Hedwigia (in press).

44. U. Geissler, Die Variabilität der Schalenmerkmale bei den Diatomeen. Nova Hedwigia 19, 623 (1970a).

45. U. Geissler, Die Schalenmerkmale der diatomeen-Ursachen ihrer variabilität und bedeutung für die taxonomie. Nova Hedwigia, Beih. 31, 511 (1970b).
46. U. Geissler, Experimentelle untersuchungen zur variabilität der schalenmerkmale bei einigen zentrischen Sü $\beta$ wasser-diatomeen. 1. Der einflu $\beta$ unterschiedlicher salzkonzentrationen auf den valvadurchmesser von Stephanodiscus hantzschii grunow. Nova Hedwigia, Beih. 73, 211 (1982).

47. U. Geissler, Experimental investigations on the variability of frustule characteristics of several freshwater diatoms. 2. The influence of different salt concentrations on some valve structures of Stephanodiscus hantzschii grunow. In Proceedings of the 8th International Diatom Symposium, Paris 1984, edited by M. Ricard Koeltz, Koenigstein (1986), pp. 59-66.

48. A.-M. Schmid, Morphologische und physiologische untersuchungen an diatomeen des neusiedlerSees: II. Licht- und rasterelektronenemikroskopische schalenanalyse der umweltabhängigen zyklomorphose von Anomoeoneis sphaerophora (KG.) Pfitzer. Nova Hedwigia 28, 309 (1976).

49. F. Dellaert and R. Beer, A developmental model for the evolution of complete autonomous agents. In Proceedings of the Simulation of Adaptive Behaviour (SAB '96) (1996).

50. F. Dellaert and R. Beer, Towards an evolvable model of development for autonomous agent synthesis. In Artificial Life IV, Proceedings of the 4th International Workshop on the Synthesis and Simulation of Living Systems, MIT Press, Cambridge, MA (1994). 